\title{
Syk Inhibitors: New Computational Insights into Their Intraerythrocytic Action in Plasmodium falciparum Malaria
}

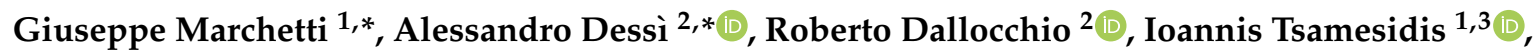 \\ Maria Carmina Pau ${ }^{1}$, Francesco Michelangelo Turrini ${ }^{4}$ and Antonella Pantaleo ${ }^{1}$ (D) \\ 1 Department of Biomedical Sciences, University of Sassari, 07100 Sassari, Italy; johntsame@gmail.com (I.T.); \\ paumc81@tiscali.it (M.C.P.); apantaleo@uniss.it (A.P.) \\ 2 National Research Council (CNR) Institute of Biomolecular Chemistry, 07100 Sassari, Italy; \\ roberto.dallocchio@cnr.it \\ 3 UMR 152 Pharma-Dev, Université de Toulouse III, IRD, UPS, 31000 Toulouse, France \\ 4 Department of Oncology, University of Turin, 10126 Turin, Italy; francesco.turrini@unito.it \\ * Correspondence: gmarchetti@uniss.it (G.M.); alessandro.dessi@cnr.it (A.D.)
}

Received: 17 July 2020; Accepted: 18 September 2020; Published: 23 September 2020

\begin{abstract}
Resistance to antimalarial drugs has spread rapidly over the past few decades. The WHO recommends artemisinin-based combination therapies for the treatment of uncomplicated malaria, but unfortunately these approaches are losing their efficacy in large areas of Southeast Asia. In 2016, artemisinin resistance was confirmed in 5 countries of the Greater Mekong subregion. We focused our study on Syk inhibitors as antimalarial drugs. The Syk protein is present in human erythrocytes, and the membrane of protein band 3 is its major target following activation by oxidant stress. Tyr phosphorylation of band 3 occurs during $P$. falciparum growth, leading to the release of microparticles containing hemicromes and structural weakening of the host cell membrane, simplifying merozoite reinfection. Syk inhibitors block these events by interacting with the Syk protein's catalytic site. We performed in vitro proteomics and in silico studies and compared the results. In vitro studies were based on treatment of the parasite's cellular cultures with different concentrations of Syk inhibitors, while proteomics studies were focused on the Tyr phosphorylation of band 3 by Syk protein with the same concentrations of drugs. In silico studies were based on different molecular modeling approaches in order to analyze and optimize the ligand-protein interactions and obtain the highest efficacy in vitro. In the presence of Syk inhibitors, we observed a marked decrease of band 3 Tyr phosphorylation according to the increase of the drug's concentration. Our studies could be useful for the structural optimization of these compounds and for the design of novel Syk inhibitors in the future.
\end{abstract}

Keywords: band 3; red blood cells; antimalarial drugs; molecular docking; molecular dynamics

\section{Introduction}

Spleen tyrosine kinase (Syk) is a cytosolic non-receptor tyrosine kinase that functions downstream of antigen receptors in immune cells such as mast cells, B lymphocytes, and macrophages. Syk is a crucial signal transducer of activated immunoreceptors in multiple downstream events, which differ depending on the cell type, including proliferation, differentiation, and phagocytosis [1-3]. Syk function might, therefore, be an attractive target for therapeutic interventions for autoimmune or inflammation diseases [4]. Syk is composed of two Src homology tandem domains, defined as N-SH2 and C-SH2 [5]; these are important for activity regulation and for localizing this kinase in the cell membrane. The tandem SH2 ( $\mathrm{tSH} 2$ ) module is also separated by an inter-SH2 linker of 50 amino acids. This is the 
most conserved region in the kinase family, with 65\% sequence homology. Additionally, tSH2 presents an $\alpha$-helix, which has an important role in protein-protein interactions and serves as a docking platform for tyrosine-based immune receptor activating motifs (ITAMs), which are displayed on the cytosolic side of the plasma membrane [6-8]. An interdomain linker of 80-100 amino acids is located between $\mathrm{C}-\mathrm{SH} 2$ and the catalytic domain. This interdomain is important in regulating kinase activity because it contains phosphotyrosine residues. A catalytic domain or SH1 containing 300 amino acids follows the interdomain linker. It contains the binding sites for ATP and two autophosphorylation sites (Tyr525 and Tyr526) [9]. Syk protein ends with a C-terminal tail, the function of which is currently unidentified.

During previous studies of human erythrocyte membranes, we observed that the erythrocytes possess a mechanism that is involved in the expulsion of denatured hemoglobin, requiring the activation of Syk [10-14]. This function could play a role in the process of asexual P. falciparum growth, as malaria parasites exert oxidative stress in erythrocytes, causing denaturation of hemoglobin, the oxidation of band 3, and its subsequent phosphorylation by Syk [15,16]. The protein band 3 (also known as the anion exchanger, AE1) constitutes the major attachment site of the spectrin-based cytoskeleton to the erythrocyte's lipid bilayer, and thereby contributes critically to the stability of the red cell membrane $[13,17]$. Under steady conditions, this linkage confers to the membrane the required elasticity and mechanical stability. The oxidation of band 3 and its subsequent phosphorylation by Syk kinase cause its detachment from the cytoskeleton and the destabilization of the membrane with the release of microvesicles $[10,14]$. Scheme 1 shows a schematic model representing the proposed mechanism of action.

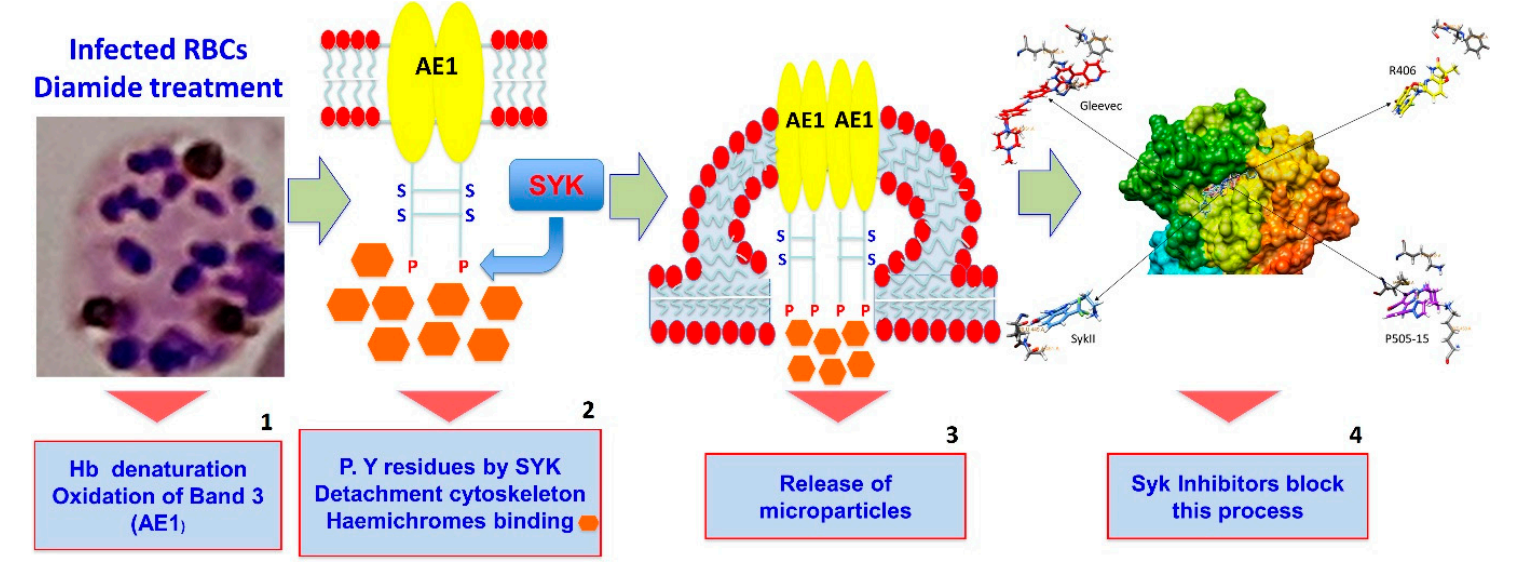

Scheme 1. Schematic model of the proposed mechanism of Syk inhibitor action. (1) Diamide treatment induces band 3 oxidation and hemoglobin denaturation. (2) Syk binds to band 3 and catalyzes band 3 cytoplasmic domain tyrosine phosphorylation, causing its detachment from the cytoskeleton.

(3) Oxidized and phosphorylated band 3 forms large clusters, which are released in microparticles through the vesiculation. (4) Syk inhibitors block this process.

Taking in consideration that Syk kinase inhibitors block the expulsion of denatured hemoglobin and its accumulation inside the parasitized erythrocytes [15-17], more knowledge of the mechanisms responsible for the protein-ligand recognition and binding will facilitate the design, development, and discovery of a new promising class of antimalarial drugs.

We first characterized the ligands with the aim of screening new drugs more efficiently in order to cure malaria, using quantum mechanics $(\mathrm{QM})$ and molecular descriptors to assess the electronic density, molecular electrostatic potential (MEP), and the charge distribution. Molecular modelling approaches, such as docking and molecular dynamics (MD) simulation [18,19], were performed to analyze the binding mode of Syk/ligands. In an effort to pursue a more unbiased approach towards identifying protein tyrosine kinase (PTK) inhibitors with antimalaria activity, we screened some ATP-competitive inhibitors of Syk characterized by different $\mathrm{IC}_{50 \mathrm{~s}}$ (Half maximal inhibitory concentrations) for the Syk 
catalytic subunits [17]. Figure 1 shows the chemical structures and the $\mathrm{IC}_{50 \text { s }}$ values of Imatinib, R406, Syk inhibitor II, and P505-15.

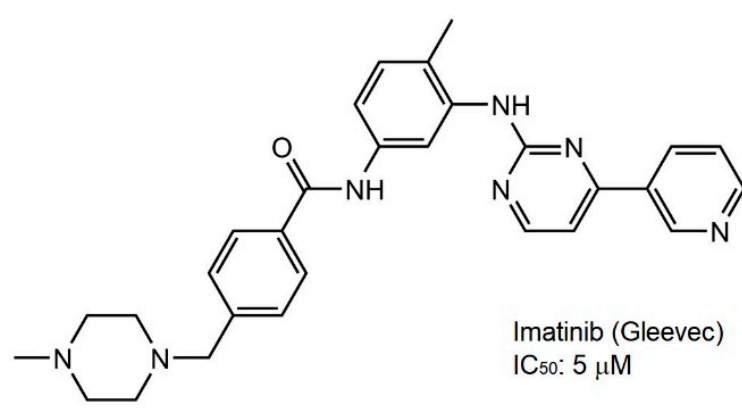<smiles>COc1cc(Nc2ncc(F)c(Nc3ccc4c(n3)NC(=O)C(C)(C)O4)n2)cc(OC)c1OC</smiles>
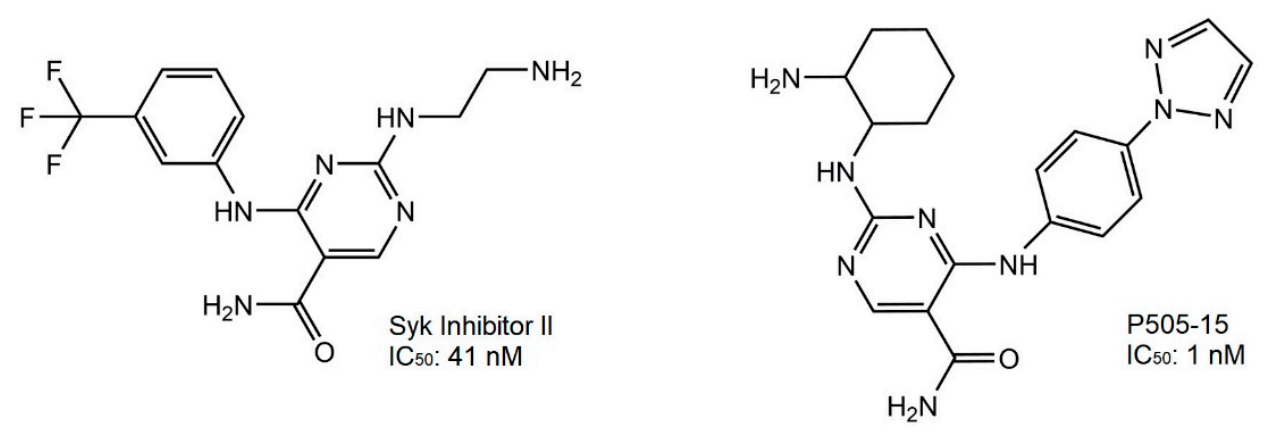

Figure 1. Chemical structures and $\mathrm{IC}_{50 \text { s }}$ for the Syk catalytics subunits of Imatinib, R406, Syk inhibitor II, and P505-15.

Imatinib, sold under the brand names Gleevec, is a well-tolerated tyrosine kinase inhibitor. It is FDA-approved for use in children [20-22] and prevents parasite-induced tyrosine phosphorylation of band 3 and terminates $P$. falciparum parasitemia in vitro by blocking parasite egress at clinically relevant concentrations [15]. This drug is also used for the treatment of chronic myeloid leukemia (CML), acute lymphoblastic leukemia (ALL), and gastrointestinal stromal tumor (GIST). R406 (tamatinib) is an active metabolite of prodrug R788 (fostamatinib), which has already been used in clinical trials for rheumatoid arthritis [23], autoimmune thrombocytopenia [24], autoimmune hemolytic anemia, IgA nephropathy, and lymphoma $[25,26]$.

P505-15 is a candidate drug that has already been used in in vivo studies in mice for treatment of rheumatoid arthritis, non-Hodgkin lymphoma (NHL), and chronic lymphocytic leukemia (CLL) [27,28]. Syk inhibitor II is already used for inhibition of serotonin (5-HT) release in rat basophilic leukemia (RBL) cells and to treat allergic diseases [29,30].

Here, we document the interactions between Syk and its ligands in order to understand the biology at the molecular level, with the aim of improving and modifying the compounds' structures and discovering new drugs to inhibit infected RBCs.

\section{Results and Discussion}

\subsection{Densitometric Analysis of Band 3 Tyrosine Phosphorylation in Diamide-Treated Erythrocytes after} Treatment with Syk Inhibitors

In vitro studies have shown that diamide treatment increases the band 3 tyrosine phosphorylation state, suggesting a possible functional connection between membrane oxidative damage and modulation of signal transduction pathways involving kinases or phosphatases [31,32]. To better understand the relationship between the activity of Syk inhibitors and their abilities to reduce band 3 tyrosine phosphorylation, we carried out experiments using $2 \mathrm{mM}$ diamide as the control (Figure 2A-D, lane 2) and $2 \mathrm{mM}$ diamide in presence of increasing Syk inhibitor concentration ranging from $0.2 \mu \mathrm{M}$ to $10 \mu \mathrm{M}$ (Figure 2A-D, lanes 3-9). As we expected, in accordance with previous reports, diamide caused a rapid 
band 3 Tyr phosphorylation, without any other phosphorylative changes occurring in erythrocyte membrane proteins [11,33], while Syk inhibitors led to a substantial decrease of band 3 phosphorylation $(95-250 \mathrm{KDa})$ related to the increasing amounts of inhibitors. This trend is clearly evident at $95 \mathrm{KDa}$ bands (phosphorylated band 3).

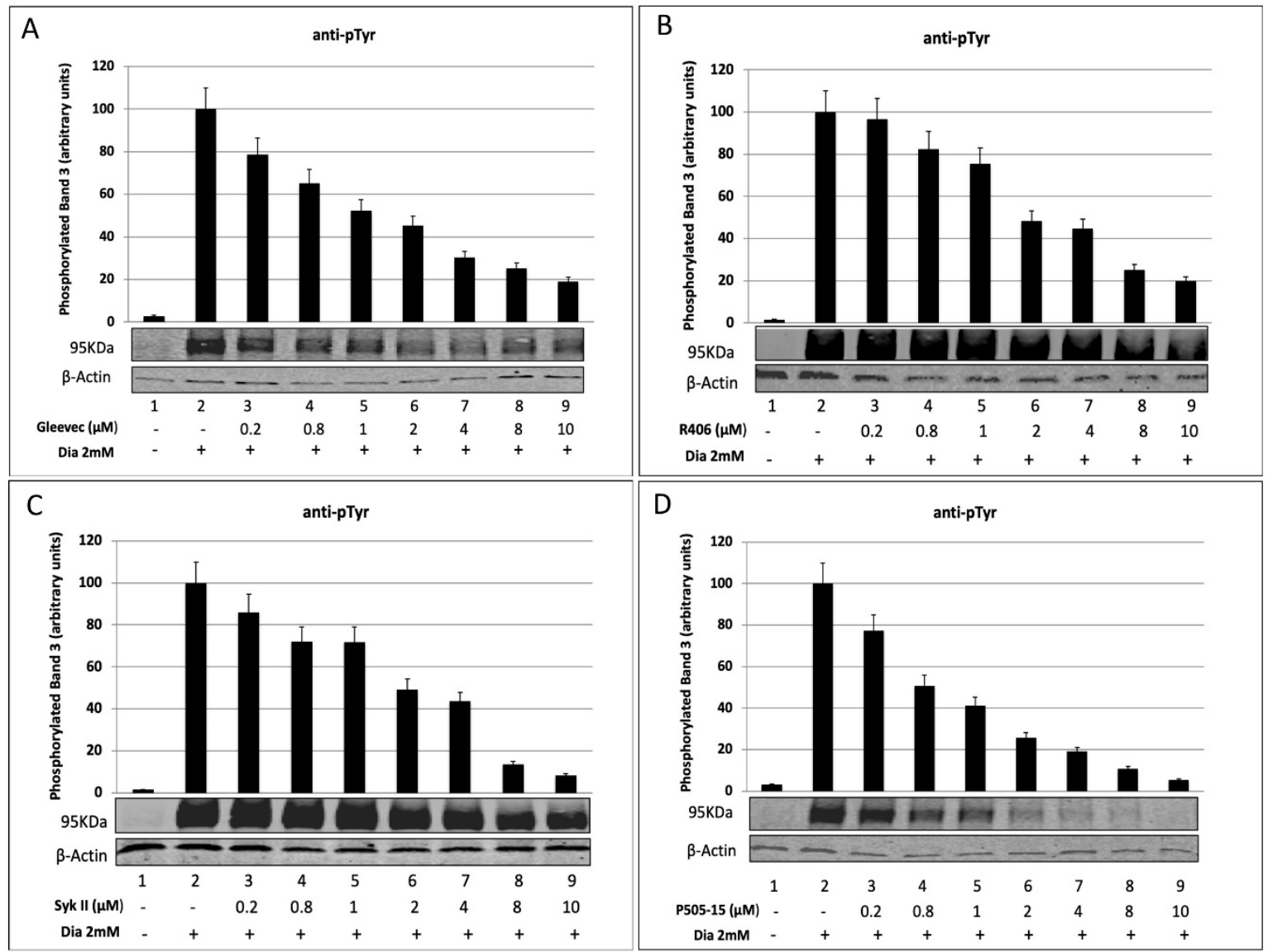

Figure 2. Dose-response course of erythrocyte membrane proteins treated with an oxidant agent and Syk inhibitors related to quantitative analysis of band 3 tyrosine phosphorylation. Erythrocytes were treated with $2 \mathrm{mM}$ diamide (Dia) and different concentrations of the Syk inhibitors $(0-10 \mu \mathrm{M})$ (A) Gleevec, (B) R406, (C) Syk II, and (D) P505-15. Lane 1 shows the untreateded control sample. Erythrocytes were separated by $8 \%$ SDS-PAGE, blotted on a nitrocellulose membrane, and stained with antiphosphotyrosine (apTyr) antibodies. Images were acquired using a laser IR fluorescence detector (Odyssey, Licor, USA). Band 3 Tyr phosphorylation was quantified using Image J software. Values are the means \pm for four independent experiments, normalized to total beta-actin levels. All graphs show relative phosphorylation, expressed as a percentage of the maximum observed in each experiment $(100 \%)$. The error bars represent the standard deviation (SD) of the data.

All densitometry analyses performed on membranes scanned on the Odyssey CLx were done using Odyssey 3.0 software, confirming the large decreases of Tyr phosphorylation levels in band 3 residues caused by Syk protein. Diamide-treated erythrocytes (Figure 2, lane 2) showed high levels of phosphorylation due to the oxidative stress conditions. All the tested Syk inhibitors efficiently suppressed band 3 phosphorylation (Figure $2 \mathrm{~A}-\mathrm{D}$, lanes 3-9). Table 1 shows the $\mathrm{IC}_{50}$ values obtained by densitometric analysis; these results were in agreement with those obtained in previous published studies treating RBCs with different concentrations of each drug and quantitating residual parasitemia 24 and $48 \mathrm{~h}$ later (Table 2) [15,17]. P505-15 was the most potent Syk inhibitor, with an $\mathrm{IC}_{50}$ of $0.64 \mu \mathrm{M}$, while Syk II was the least efficient, with an $\mathrm{IC}_{50}$ of $1.72 \mu \mathrm{M}$. 
Table 1. $\mathrm{IC}_{50}$ values obtained from the densitometry analysis performed on anti-p-Tyr Western blotting membranes.

\begin{tabular}{cc}
\hline Syk Inhibitors & IC50 $(\mu \mathrm{M})$ \\
\hline P505-15 & 0.64 \\
Gleevec & 0.77 \\
R406 & 0.83 \\
Syk II & 1.72 \\
\hline
\end{tabular}

Table 2. Approximate $\mathrm{IC}_{50}$ values for each drug were determined by treating ring-stage cultures of $P$. falciparum, Palo Alto strain, with different concentrations of each drug and by quantitating residual parasitemia 24 and $48 \mathrm{~h}$ later.

\begin{tabular}{ccccc}
\hline \multirow{2}{*}{ Palo Alto Strain } & \multicolumn{2}{c}{$2 \mathbf{h}$} & \multicolumn{2}{c}{$\mathbf{4 8} \mathbf{h}$} \\
\cline { 2 - 5 } & IC50 $(\mu \mathbf{M})$ & Range $(\mu \mathrm{M})$ & IC50 $(\mu \mathbf{M})$ & Range $(\mu \mathbf{M})$ \\
\hline P505-15 & $0.83 \pm 0.06$ & $0.78-0.90$ & $0.49 \pm 0.07$ & $0.42-0.61$ \\
R406 & $2.62 \pm 0.83$ & $1.42-3.85$ & $0.55 \pm 0.19$ & $0.25-0.92$ \\
Gleevec & $3.81 \pm 0.55$ & $3.24-4.95$ & $1.55 \pm 0.13$ & $1.32-1.74$ \\
SYK II & $5.01 \pm 0.44$ & $4.65-5.87$ & $0.90 \pm 0.16$ & $0.82-1.25$ \\
\hline
\end{tabular}

\subsection{Assessment of Syk Inhibitor Efficacy through Computational Studies}

To contribute to the understanding of the mechanism of Syk kinase inhibitors in the treatment of malaria and the possible role of Syk inhibition in parasite growth via suppression of band 3 phosphorylation, we also performed computational studies. This kind of approach has been used by many research groups around the world, e.g., by the "Global Online Fight Against Malaria" project of The Scripps Research Institute (TSRI) in La Jolla, CA, U.S.A. In this study, we used the same techniques and the same software, with the aim of speeding up the knowledge acquisition and the process of antimalarial drug discovery. Antimalarial drugs are as effective as artemisinin derivatives, thus providing new hope for the control of malaria.

Previous studies showing the conformational research on R406 [34], Gleevec, Syk inhibitor II, and P505-15 inhibitors [35] were taken into consideration to select the conformation level with the lowest energies and best stability. The highest occupied molecular orbital-lowest unoccupied molecular orbital (HOMO-LUMO) distribution values, energy values, and energy gaps for the hit molecules were computed in order to understand the biological activity [36] (Figure 3).

Figure 4 shows the molecular electrostatic potential (MEP) computed using GaussView 5.0, which allowed us to visualize several sites with abundant electrons by analyzing the charge distributions within a molecule in three dimensions. These maps were used to predict how molecules interact with the binding site of Syk.

The X-ray crystal structure for 4FL2.pdb (2.19 resolution) was available in the RCSB PDB database; this structure was the most complete, although the active site compared to other structures found in the same database was forced by an activation loop.

The docking results obtained from the crystal structure of Syk (4FL2) in the complex with ligands showed conserved H-bond interactions (Table 3); however, a different disposition of ligands in the pocket was observed compared to the poses of the crystal structure of reference.

Although the ligands have a common pattern of interaction with Syk, which is known for all tyrosine kinases [37], our molecules presented different rotations and torsions in the site binding, with the exception of P505-15 [38], which showed an RMSD of 1.39 Å related to its reference (PDB accession number 4RX9), (Figure 5). 
Table 3. The data shown represent the H-bond binding found in docking analyses from the different inhibitors (Gleevec, R406, Syk II, and P505-15) interacting with Syk protein. Abbreviations: hydrogen donor, HD; oxygen acceptor, OA; nitrogen acceptor, NA; Debie, D; and Angstrom, A. The cross-bridge $\mathrm{H}$-bond interactions with the same aa are listed in bold".

\begin{tabular}{|c|c|c|c|c|c|c|c|c|}
\hline \multicolumn{9}{|c|}{ H-Bond Interaction } \\
\hline Ligands & Pose & $\%$ & H-Bond & Ligands Atom & Protein Atom & Distance (Å) & $\log P$ & D. M. (Debye) \\
\hline \multirow{4}{*}{ Gleevec } & \multirow{4}{*}{1} & \multirow{4}{*}{73} & \multirow{4}{*}{4} & N33(NA) & Lys402:HZ1(HD) & 2.217 & \multirow{4}{*}{3.83} & \multirow{4}{*}{5.1101} \\
\hline & & & & O10(OA) & Ala451:HN(HD) & 2.393 & & \\
\hline & & & & N38(NA) & Arg498:HE(HD) & 2.147 & & \\
\hline & & & & H27(HD) & Asp512:OD2(OA) & 1.995 & & \\
\hline \multirow{3}{*}{ R406 } & \multirow{3}{*}{11} & \multirow{3}{*}{16} & \multirow{3}{*}{3} & H9(HD) & Leu377:O(OA) & 1.875 & \multirow{3}{*}{3.37} & \multirow{3}{*}{3.4870} \\
\hline & & & & H25(HD) & Ala451:O(OA) & 2.262 & & \\
\hline & & & & $\mathrm{O} 36(\mathrm{OA})$ & Ala451:HN(HD) & 2.317 & & \\
\hline \multirow{7}{*}{ SykII } & \multirow{7}{*}{1} & \multirow{7}{*}{56} & \multirow{7}{*}{7} & $\mathrm{H} 23(\mathrm{HD})$ & Glu449:O(OA) & 2.075 & \multirow{7}{*}{1.22} & \multirow{7}{*}{4.4175} \\
\hline & & & & $\mathrm{H} 24(\mathrm{HD})$ & Glu449:O(OA) & 2.233 & & \\
\hline & & & & $\mathrm{O} 25(\mathrm{OA})$ & Ala451:HN(HD) & 2.299 & & \\
\hline & & & & H29(HD) & Arg498:O(OA) & 2.063 & & \\
\hline & & & & H30(HD) & Ser511:HG(HD) & 2.558 & & \\
\hline & & & & H8(HD) & Asp512:OD2(OA) & 2.191 & & \\
\hline & & & & H30(HD) & Asp512:OD2(OA) & 2.025 & & \\
\hline \multirow{4}{*}{ P505-15 } & \multirow{4}{*}{8} & \multirow{4}{*}{37} & \multirow{4}{*}{4} & H8(HD) & Ala451:O(OA) & 2.301 & \multirow{4}{*}{1.02} & \multirow{4}{*}{2.4285} \\
\hline & & & & O21(OA) & Ala451:HN(HD) & 1.888 & & \\
\hline & & & & H23(HD) & Glu449:O(OA) & 1.940 & & \\
\hline & & & & H24(HD) & Glu449:O(OA) & 2.448 & & \\
\hline
\end{tabular}

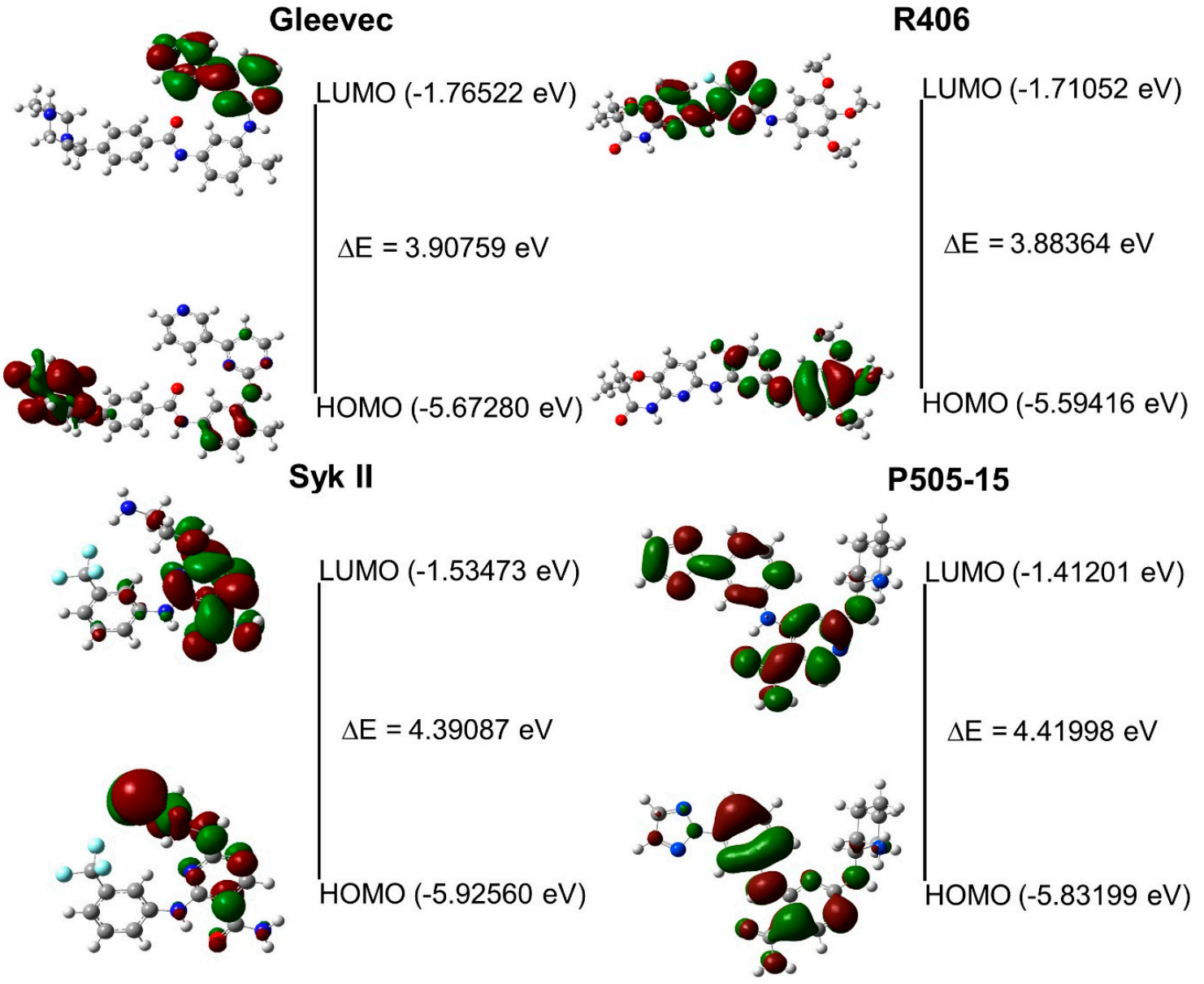

Figure 3. The most probable statistical positions in the highest occupied molecular orbital-lowest unoccupied molecular orbital (HOMO-LUMO) descriptor values. 


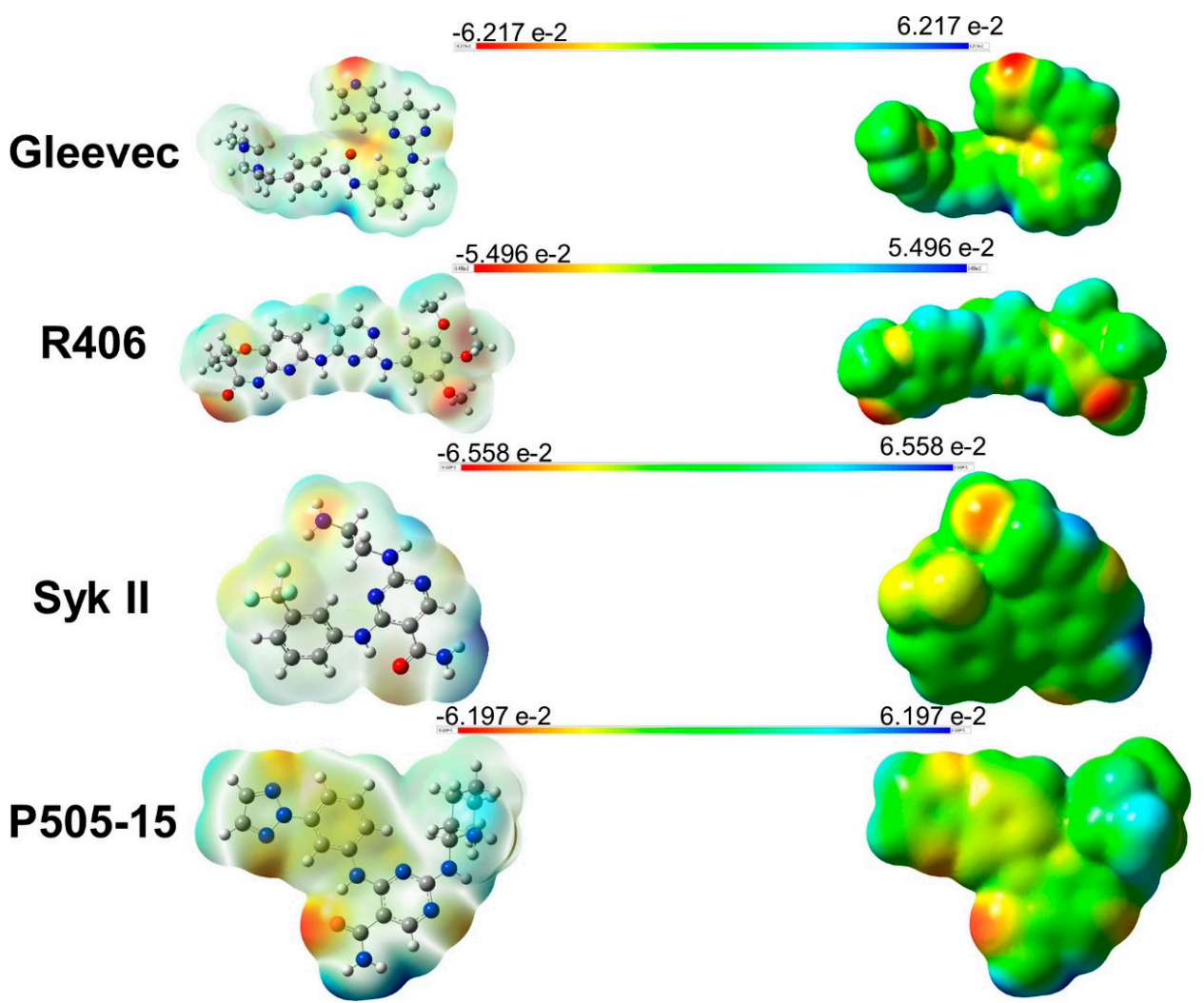

Figure 4. Molecular electrostatic potential (MEP) of surface Syk inhibitors. The color scheme ranges from red (negative potential) via green (zero potential) to blue (positive potential). The unit of isosurface potential is electrostatic potential $(\mathrm{eV})$.

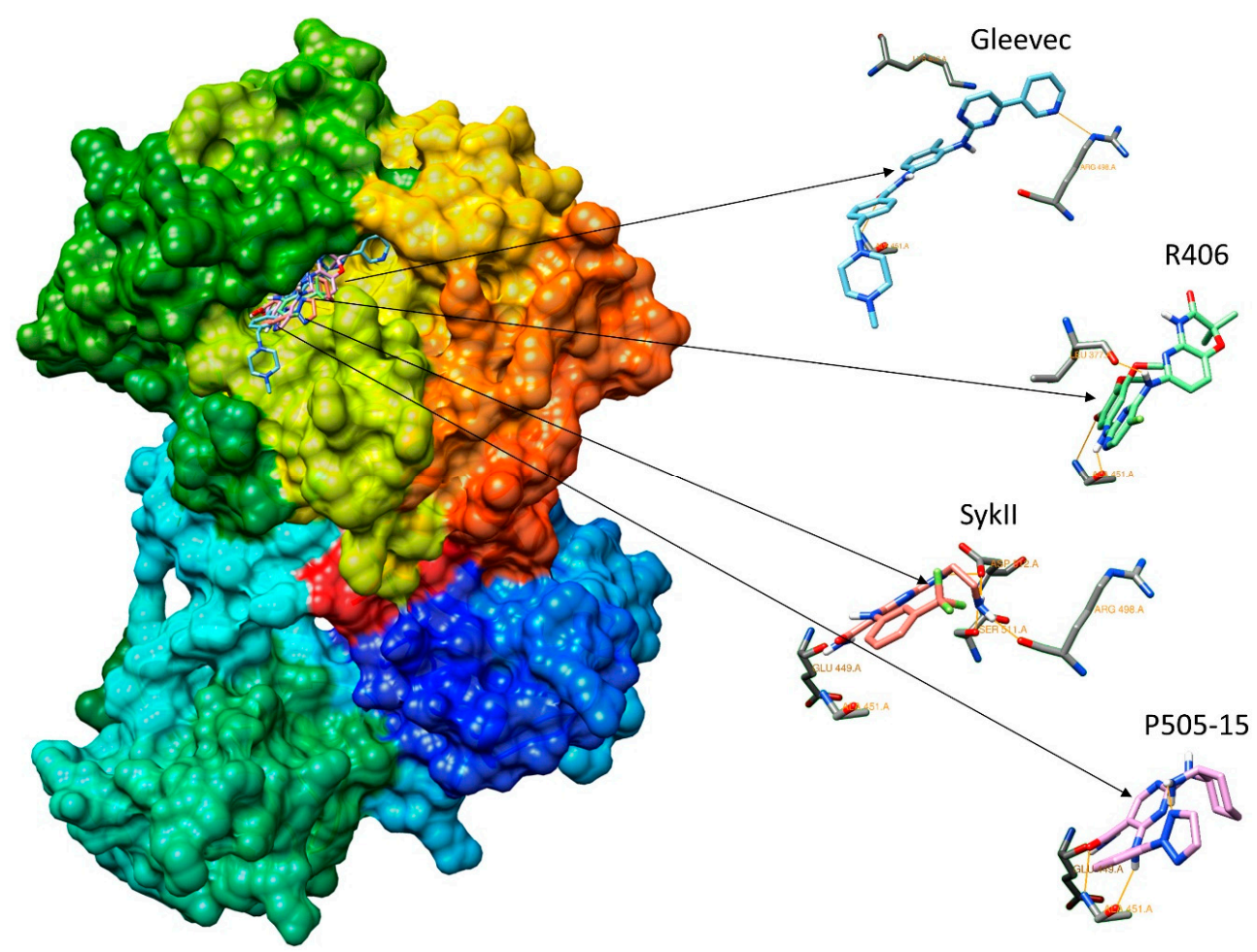

Figure 5. The 3D surface structure of Syk protein, showing Syk inhibitors interacting in the catalytic site. The compounds, with the main H-bond interactions, were reported alone, outside of the pocket of binding. 
Further analysis of the docking demonstrated that the amino acids Leu377, Val385, Ala400, Met448, Met450, Ala451, Gly454, and Leu501 present in the active site of the protein interacted with all tested Syk inhibitors. Table 4 shows an interesting hydrophobic interaction of Tyr525 with Gleevec, representing an autophosphorylation site of Syk protein that was previously found [39]. Gleevec interacts through H-bonds with Lys402, Arg498, and Asp512. R406 shows H-bonds with Leu377 and Ala451. Syk II interacts with Glu449, Ala451, Arg498, Ser511, and Asp512, while P505-15 shows H-bonds with Glu449 and Ala451.

Table 4. Hydrophobic interactions and H-bonds between Syk inhibitors and proteins. The bonds are shown highlighted with * (1 H-bond) and with ** (2 H-bonds). Amino acids that are underlined have a high level of Syk specificity. The amino acid Tyr525 is double underlined, which is an autophosphorylation site of Syk protein that forms an interesting interaction with Gleevec.

\begin{tabular}{cccc}
\hline R406 & Syk II & Gleevec & P505-15 \\
\hline Leu377* & Leu377 & Arg338 & Leu377 \\
Gly378 & Gly378 & Leu377 & Val385 \\
Ser379 & Val385 & Ser379 & Ala400 \\
Gly380 & Ala400 & Gly380 & Met448 \\
Val385 & Lys402 & Asn381 & Glu449** \\
Ala400 & Met448 & Phe382 & Met450 \\
Lys402 & Glu449 ** & Val385 & Ala451** \\
Val433 & $\underline{\text { Met450 }}$ & Ala400 & Glu452 \\
Met448 & Ala451* & Lys402* & Gly454 \\
Glu449 & Gly454 & Met448 & Pro455 \\
Met450 & Pro455 & Met450 & Lys458 \\
Ala451*** & Lys458 & Ala451* & Leu501 \\
Glu452 & Arg498* & Leu453 & \\
Gly454 & Leu501 & Gly454 & \\
Pro455 & Ser511* & Arg498* & \\
\hline Lys458 & Asp512** & Asn499 & \\
Leu501 & & Leu501 & \\
Asp512 & & Ser511 & \\
& & Asp512* & \\
& & Tyr525 & \\
& & His531 & \\
\hline
\end{tabular}

The different interactions between ligands and proteins observed through their docking and different conformations might be due to the fact that the pocket is capped by an activation loop, causing a steric hindrance. Due to the presence of this buried active site, we considered the 4FL2 crystal's structure in its active conformation compared to the other proteins that we have analyzed in the RCSB database, where their binding pockets were opened.

The main differences among these structures are in the activation loops (a.a. 520-534) [40], which translate into the active conformation of Syk, closing the ligands in the pocket. The active conformation is characterized for containing the Syk activation loop that closes the ATP-binding pocket once a ligand interacts with the amino acids in the site.

The estimation of the inhibition constants (Ki) of all tested compounds obtained by docking simulation showed that the lowest value was for Gleevec $(13.65 \mathrm{nM})$. This result was unexpected; we assume that it could be due to the increasing number of protein-ligand interactions, which enhance the stability inside the pocket. Table 5 shows the binding energy and Ki values obtained by computational analysis. These data, which were obtained by combining the results of both tests, are useful in understanding the role of Syk inhibitors and their ability to enable the implementation of in vitro testing. 
Table 5. Data showing the binding energy and inhibition constant (Ki) values obtained from the docking analysis of Syk inhibitors with 4FL2. Abbreviations: mean binding energy, M.B.E; estimated free energy of binding, E.F.E.B; estimated inhibition constant, E.I.C.

\begin{tabular}{cccc}
\hline Ligand & M.B.E & E.F.E.B & E.I.C, Ki \\
\hline Gleevec & -10.57 & -10.73 & $13.65 \mathrm{nM}$ \\
P505-15 & -7.69 & -8.81 & $346.88 \mathrm{nM}$ \\
R406 & -7.28 & -7.94 & $1.50 \mu \mathrm{M}$ \\
SykII & -6.80 & -6.95 & $8.03 \mu \mathrm{M}$ \\
\hline
\end{tabular}

Dynamic molecular analyses were performed to compute the ligands' trajectory and their interactions with the protein. P505-15 and R406, both alone or in combination with the crystal structure of Syk (4FL2), showed higher chemical stability if compared to Gleevec and Syk II, showing a lower conformation change in the pocket.

Further evidence is shown in Figure 6, where the high variability of the conformations of Gleevec and Syk II, both alone or in combination, is evident from the peaks, as compared to P505-15 and R406. Gleevec shows significant variation of the structure disposition, with a value range of 1.5 to $3.8 \AA$.

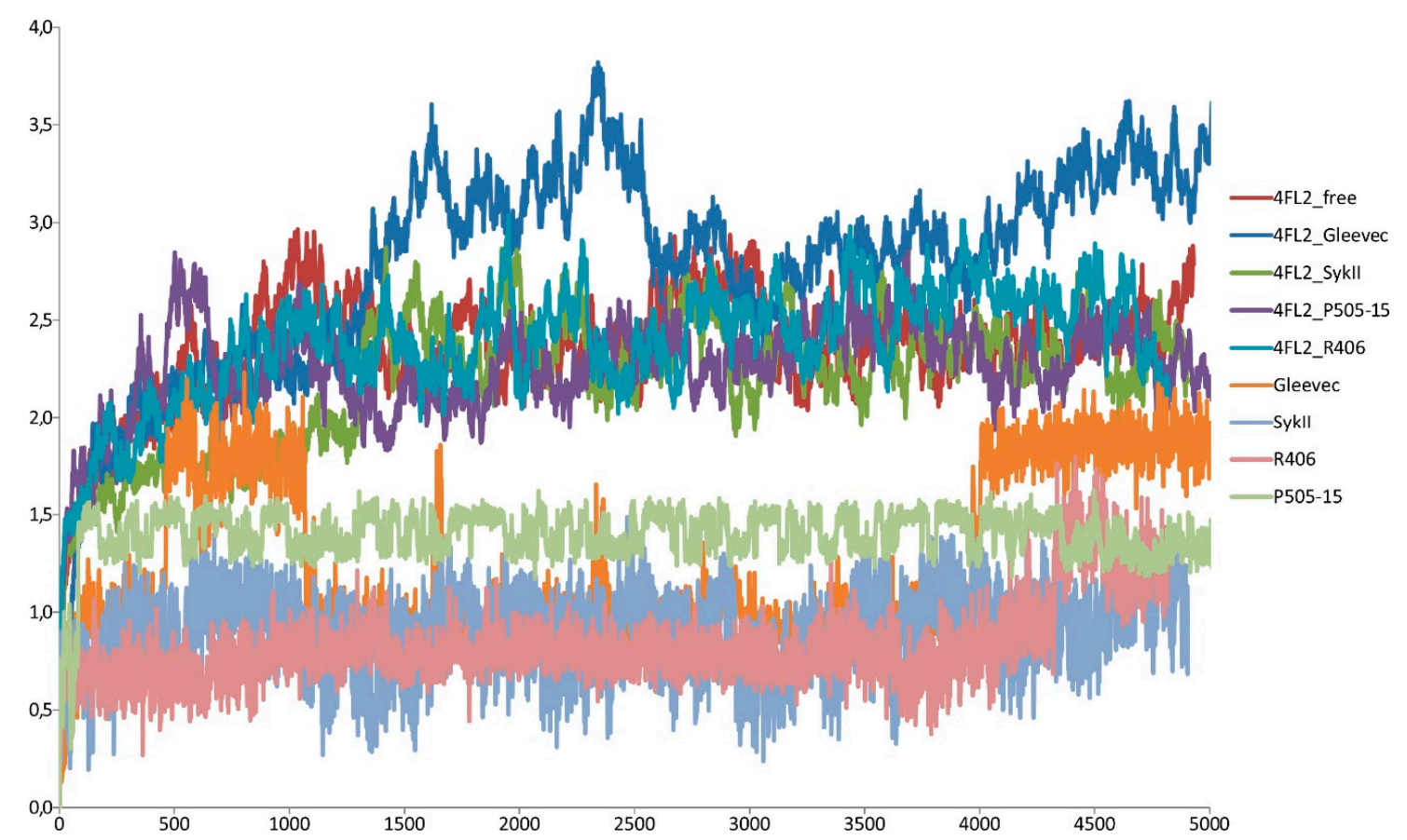

Figure 6. Root mean square deviation (RMSD) values (values on the $y$-axis reported in $\AA$ ) for all deviation atoms calculated over $10 \mathrm{~ns}$, with the values on the $x$-axis reported as steps ( 1 step $=2 \mathrm{ps}$ ) of 4FL2, the compounds alone, and the four complexes-4FL2-Gleevec, 4FL2-SykII, 4FL2-R406, 4FL2-P505-15.

Based on these data, we could establish the potential mechanism of the interactions between the competitive ATP inhibitors and the binding site of the protein, which is involved in the inhibition process.

It should be noted that the autophosphorylation site Tyr 525 interacts only with Gleevec, which could explain the different inhibition levels observed in in vitro $\left(\mathrm{IC}_{50} 3.81 \mu \mathrm{M}\right)$ and in silico (Ki $13.65 \mathrm{nM}$ ) studies. Furthermore, the data demonstrated that most of the amino acid interactions established by Gleevec could be relevant in providing better chemical stability and lower binding energy in silico, although this ligand is not specific to Syk. In this paper, we also report that all Syk inhibitors interact with Met450, Leu453, and Pro455; these amino acids are of great importance because of their high levels of Syk specificity [41-43]. 
We postulate that all of the discrepancies between the different methodologies used in this study could be due to numerous biological variables that occur in cultures of infected RBCs (i.e., RBC membrane transport, infection by parasites, ATP consumption) and to the difficulties founded in in silico studies caused by the inability to use fixed concentrations for the tested compounds.

A good correlation was found for the $\mathrm{IC}_{50}$ values among in vitro and in silico experiments; R406 and P505-15 followed the same trend and were more effective. Gleevec demonstrated major interactions and had the lowest $\mathrm{Ki}$ value in the docking analysis. The free binding energy values confirmed the high affinity of Syk inhibitors toward the catalytic site. The computed energy gap between the HOMO and LUMO was used to determine the chemical stability and molecular features of all tested compounds. All of this information will be useful in facilitating the selection of similar Syk inhibitors and antimalarial compounds. Based on these conclusions and the fact that the parasite cannot mutate an erythrocyte tyrosine kinase, we can speculate that Syk inhibitors could contribute to the potency levels of ACTs. It must also be noted that none of the currently used antimalaria drugs prevent the rupture of infected erythrocytes and reinvasion or inhibit host targets that cannot be mutated by the parasite in order to develop drug resistance.

Future computational and proteomic analyses will be necessary to better understand the importance of some amino acids in the pattern of interaction, basing the research of new compounds on the catalytic site features in order to improve their in vitro efficacy.

\section{Materials and Methods}

In this work, we performed a series of in vitro experiments in infected RBCs in order to investigate the biological activity of different Syk inhibitors on P. falciparum cultures and evaluate their $\mathrm{IC}_{50}$ concentrations. We measured their activity at varying concentrations, for various durations, and at different parasite stages. Furthermore, in proteomics studies, the levels of Tyr phosphorylation in oxidized RBCs were quantified using diamide (a reagent that oxidizes sulphydryl groups to the disulfide form). These analyses were followed by the identification of amino acid interactions in the catalytic site of Syk protein through in silico studies.

\subsection{In Vitro Experiments}

Freshly drawn blood $(\mathrm{R}+)$ samples from healthy adults were used to sustain the parasites in in vitro cultures. Healthy adults provided written, informed consent in ASL.1-Sassari. The in vitro studies were conducted using P. falciparum (Palo Alto strain), as previously reported for the Palo Alto (PA) strain (mycoplasma-free) according to standard protocols [44,45]. The Palo Alto (PA) strain is a reference parasite strain that is used to study various antimalarial drugs in P. falciparum. The PA strain was isolated from a Ugandan patient and is considered a reference strain due to its high genetic stability [46].

Parasite cultures were synchronized as described by Lambros and Vanderberg [47]. Throughout this procedure, $P$. falciparum cultures maintained synchronicity for 2-3 cycles. For all experiments, mature parasites (shizonts and segmenters) after Percoll separation [48] were added to washed RBCs; $12 \mathrm{~h}$ after the infection (occurring within $6 \mathrm{~h}$ ), the cultures were ready for the experimental procedures.

All experiments were carried out by starting with $2 \%$ hematocrit and $2 \%$ parasitemia. Each well of a 24-multiwell plate contained $500 \mu \mathrm{l}$ of growth medium treated with different concentrations of the drugs $(0.2,0.8,1,2,4,8,10 \mu \mathrm{M}) \mathrm{R} 406$, Syk II, Gleevec, and P505-15 for 24 and $48 \mathrm{~h}$. The parasitemia was evaluated by optic microscopy and the $\mathrm{IC}_{50}$ value of each compound was calculated using ICEstimator $1.2[49,50]$. 


\subsection{Treatment of Red Blood Cells}

Venous blood was drawn from healthy volunteers following informed consent and pelleted at $1000 \mathrm{~g}$ for $10 \mathrm{~min}$ at room temperature. After removal of the buffy coat, RBCs were again pelleted and washed 3 times with phosphate-buffered saline $(127 \mathrm{mM} \mathrm{NaCl}, 2.7 \mathrm{mM} \mathrm{KCl}, 8.1 \mathrm{mM} \mathrm{Na} 2 \mathrm{HPO} 4,1.5 \mathrm{mM}$ $\mathrm{KH} 2 \mathrm{PO} 4,20 \mathrm{mM}$ HEPES, $1 \mathrm{mM} \mathrm{MgCl2}$, and $\mathrm{pH}$ 7.4) in $5 \mathrm{mM}$ glucose (PBS glucose) to obtain packed cells. RBCs were suspended at a hematocrit level of 30\% in PBS glucose and pretreated in different experiments with Syk inhibitor II (Merck, Darmstadt, Germany.), R406 (Selleckchem, Darmstadt, Germany), and Gleevec at different concentrations $(0.2,0.8,1,2,4,8,10 \mu \mathrm{M})$ for $1 \mathrm{~h}$ at $37^{\circ} \mathrm{C}$ in the dark, then in the presence of the oxidant diamide at a $2 \mathrm{mM}$ concentration for $45 \mathrm{~min}$. For all the protocols described, untreated controls and controls treated with only $2 \mathrm{mM}$ of diamide were identically processed. To prevent further phosphorylation of band 3, after incubation we washed the cells with cold buffer and the membranes were immediately prepared.

\subsection{RBC Membrane Preparation}

Membrane proteins were prepared at $4{ }^{\circ} \mathrm{C}$ on ice as previously described [16]. Briefly, $150 \mu \mathrm{L}$ of packed RBCs was diluted into $1.5 \mathrm{~mL}$ of cold hemolysis buffer $(\mathrm{HB})(5 \mathrm{mM}$ disodium phosphate, $1 \mathrm{mM}$ EDTA, $\mathrm{pH} 8$ ), containing a protease and a phosphatase inhibitor cocktail, then washed up to 4 more times in the same buffer (until membranes became white) in a refrigerated Eppendorf microfuge at $25,000 \times \mathrm{g}$. The samples were stored frozen at $-20^{\circ} \mathrm{C}$ until use. The membrane protein content was quantified using the CD Protein Assay (Bio-Rad).

\subsection{SDS-PAGE}

To perform one-dimensional electrophoresis, membrane proteins were solubilized in Laemmli buffer [51] at a volume ratio of 1:1.30 $\mu \mathrm{g}$ of protein-to-antiphosphotyrosine. Then, the samples were put in a thermomixer at $1400 \mathrm{rpm}$ and $28^{\circ} \mathrm{C}$ for $30 \mathrm{~min}$. Next, the samples were stored at $95^{\circ} \mathrm{C}$ for $5 \mathrm{~min}$, then separated on $8 \%$ polyacrylamide gel under reducing and non-reducing conditions. The electrophoretic run was performed on the Bio-Rad Mini-Protean 3 setup.

\subsection{Western Blot Analysis}

Proteins separated by SDS-PAGE were transferred to nitrocellulose membranes as previously described with Trans-Blot Turbo Bio-Rad and then probed with antiphosphotyrosine antibody (sc7020, Santa Cruz, CA, USA). This was produced in mice in Santa Cruz, CA, USA, and was diluted to 1:2000. Secondary antibodies conjugated with infrared fluorescent dyes excitable at $680 \mathrm{~nm}$ or $800 \mathrm{~nm}$ (IRDye, Antimouse 800 CW 926-32210, Li-COR, Lincoln, NE, USA) were then used to visualize the desired antigens with a laser scanner (Odyssey, Licor, Lincoln, NE, USA). Quantitative densitometry analyses of tyrosine phosphorylation levels were carried out by analyzing Western blot images using Image $\mathrm{J}$ software. The values were expressed as arbitrary units. The rate of band 3 phosphorylation was expressed as the PTP activity and as a percentage of the maximal activity in RBCs treated with $2 \mathrm{mM}$ diamide. All graphs precisely show the relative phosphorylation, expressed as a percentage of the maximum observed in each experiment $(100 \%)$. The results show the average of four experiments, normalized to total beta-actin levels. The error bars represent the standard deviations (SDs) of the data. The $\mathrm{IC}_{50}$ values of different drugs were calculated using ICEstimator 1.2 software. 


\subsection{Molecular Mechanics (MM) and Quantum Chemicals (QC)}

Computational modelling was performed on IBM Blade Center HS22 7870 multiprocessor machines, using OS Ubuntu 16.04 or Windows 10. The small molecules were constructed with standard bond lengths and angles from the fragment database with MacroModel 5.5 [52]. Minimization of structures by conformational search was performed with the MacroModel/BachMin 6.0 program using the AMBER force field.

An extensive conformational search was further carried out using Monte Carlo energy minimization [53] (Ei-E min $<5 \mathrm{Kcal} / \mathrm{mole}$, the energy difference between the generated conformation and the current minimum).

The atomic charges were assigned using the Gasteiger-Marsili method [54]. Representative minimum energy conformations of each compound were optimized using the quantum chemistry program Gaussian 09W with the DFT B3LYP/6-311G method basis set. Visual quantum chemical calculation analysis was performed with GaussView version $5.0[55,56]$.

\subsection{Molecular Electrostatic Potential (MEP)}

The molecular electrostatic potentials (MEP) related to the dipole moment, electronegativity, and partial charges, and showing the reactivity of a molecule were computed. Positive potential values reflect nucleus predominance, while negative values represent rearrangements of electronic charges and lone pairs of electrons.

The analyzed MEP were expressed as different colors depending on the densities of organic molecules and electrophilic electrons, with red representing a negative charge and blue representing a positive charge.

\subsection{Molecular Docking}

All docking tests were performed by considering a $60 \times 60 \times 60$ grid and adopting the default grid spacing $(0.375 \AA)$, treating the docking active site as rigid and the ligands as flexible, i.e., all non-ring torsions were considered active (free to rotate).

Binding of the compounds was analyzed using MGLTools 1.5.7rc1 [57] and AutoDock 4.2 docking programs [58,59].

From the estimated free energy values of ligand binding (E.F.E.B., $\Delta \mathrm{G})$, the inhibition constant $(\mathrm{Ki})$ for each ligand was evaluated. $\mathrm{Ki}$ was calculated using the equation: $\mathrm{Ki}=\exp ((\Delta \mathrm{G} \times 1000) /(\mathrm{R} \times \mathrm{T}))$, where $\Delta \mathrm{G}$ is the docking energy, $\mathrm{R}$ (gas constant) is 1.98719 cal $\mathrm{K}-1 \mathrm{~mol}-1$, and $\mathrm{T}$ (temperature) is 298.15 K. The protein target Syk complex with the AMP-PNP ligand (PDB ID: 4FL2; resolution of $2.19 \AA$ ) was chosen, which is deposited in RCSB Protein Data Bank [60]. The structure was the most defined and complete, except for the first part of the N-terminus (a.a. 1-8) and the interdomain linker region (a.a. 265-336). The crystallographic water molecules were stripped and hydrogen atoms were added using the AutoDockTools (ADT) module.

\subsection{Molecular Dynamics (MD)}

Molecular dynamics (MD) calculations were performed to simulate the interactions with the active site of Syk protein, with the best conformation scores predicted by Autodock for all ligands. The MD protocol) for the production simulations were carried out using the Particle Mesh Ewald Molecular Dynamics (PMEMD) version included in the AMBER14 program [61], after careful relaxation of the system using minimization and equilibration protocols.

10 nanoseconds of molecular dynamics production trajectory was saved (5000 frames of 0.002 nanoseconds). The ionizable residues were set to their normal ionization states at $\mathrm{pH} 7$, while the protein atoms and all water molecules of the crystal structure were surrounded by a periodic box of TIP3P32 water molecules that extended $10 \AA$ from the protein. Counterions $\left(\mathrm{Cl}^{-}\right.$or Na$\left.{ }^{+}\right)$were placed by xleap to neutralize the system with a Ewald force field and TIP3P water [62]. 
The ff10 version of the AMBER force field was used to model the protein, and the General AMBER Force Field (GAFF) was used for the organic ligand using the Austin Model 1-Bond Charge Corrections (AM1-BCC) partial charges derived from the antechamber program of the AMBER suite. In the MD simulation protocol, the SHAKE algorithm was used to constrain all bonds involving hydrogen atoms. A non-bonded cutoff of $8.0 \AA$ was used. Langevin dynamics were used to control the temperature (300 K) using a collision frequency of $1.0 \mathrm{ps}-1$, along with isotropic position scaling to maintain the pressure (1 atm). Periodic boundary conditions were applied to simulate a continuous system. To include the contributions of long-range interactions, the particle mesh Ewald (PME) method was used with a grid spacing of $1 \AA$ combined with a fourth-order B-spline interpolation to compute the potentials and forces in between grid points. The trajectories were analyzed using the Processing Trajectory program (PTRAJ) module of AMBER.

Molecular mechanics and Poisson-Boltzmann (or generalized Born) surface area (MM/PB(GB)SA) calculations and analyses were done with the MM-PBSA program in Amber14 suite.

Graphical representation of the hypothetical positions derived from the docking calculations and the trajectory analysis of molecular dynamics calculations was performed using Chimera [63] and Visual Molecular Dynamics (VMD) [64] software.

Calculations and energy comparisons were conducted using the method proposed by Ross Walker [65].

\subsection{Validation of Molecular Docking Protocol}

The reliability of the docking approach was further verified with two methods, with one test performed by extracting the phosphoaminophosphonic acid adenylate ester (ANP) from the catalytic site of $4 \mathrm{FL} 2$, with a $2.19 \AA$ resolution crystal structure, leading the re-docking. After repositioning the ANP into the protein, the new ANP location was the same as in the original X-ray structure, with RMSD $1.54 \AA$, which was repositioned with only minimal conformational changes, hence confirming the reliability of the system (RMSD $1.54 \AA$ ). The second test was conducted by extraction of the N-\{6-[3-(piperazin-1-yl)phenyl]pyridin-2-yl\}-4-(trifluoromethyl)pyridin-2-amine (0SB) from X-ray images of 4F4P.pdb, with a $2.37 \AA$ r resolution, which was docked with the same macromolecule derived from 4FL2.pdb. After the docking, the new OSB location was the same as in the original X-ray structure, with RMSD $0.99 \AA$, which was repositioned with only minimal conformational changes, hence further confirming the reliability of the system (Figure 7). The multiple ligand-protein interactions were analyzed through a 2D diagram in LigPlot+ [66] and the RMSD values of $1.54 \AA$ and $0.99 \AA$ were consequently evaluated in ANP and OSB experiments, respectively. We could assume the validation of the docking protocol to be satisfactory, considering the values obtained were lower than $2 \AA$. 

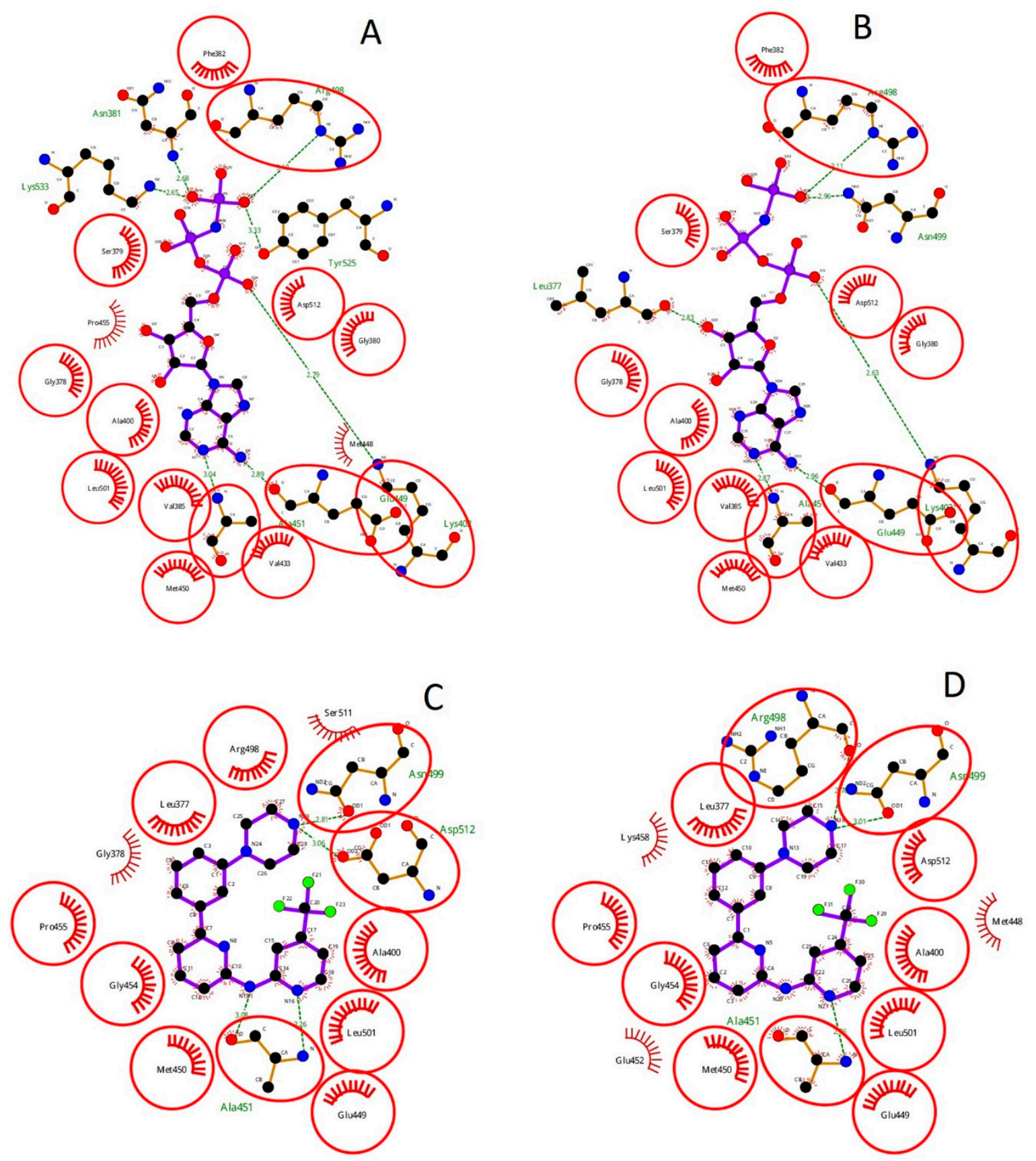

Figure 7. Two different approaches used to validate the docking analysis protocol related to X-ray images of 4FL2 (A) and 4F4P (C) crystals. The first test consisted of re-docking among 4FL2 and its ligand ANP (B), while the second test involved the docking of 4FL2 with the ligand OSB (D). The 2D diagrams were achieved through the LigPlot+ tool.

\section{Conclusions}

Molecular docking is one of the most widely used computational approaches in the design of structure-based drugs $[67,68]$. This approach can be used both to identify the correct conformation of the ligand within the target binding pocket and to estimate the interaction energy between a target and a ligand $[69,70]$. In the present study, different Syk inhibitors were investigated using different methodologies to test their efficacy in vitro and in silico as promising new antimalarial drugs to block Syk phosphorylation events in RBCs infected by parasites. Thorough the computational studies, we gathered useful information about the tested inhibitors, analyzing their chemical features and the 
patterns of interaction in the Syk protein pocket, proving their inhibitory activity in in vitro experiments. Based on the above data and other publications from our labs, we demonstrated that these compounds actually block the phosphorylation of Tyr residues in protein band 3. The in vitro experiments using a proteomic approach allowed us to notice that Syk inhibitors terminate the life cycle during the process of merozoite egress from the infected RBC, leading to a decrease of band 3 phosphorylation and avoiding the destabilization and weakening of the erythrocyte membrane. The biological data obtained by evaluating the $\mathrm{IC}_{50}$ values using Western blotting for all tested compounds confirmed the results achieved in in silico studies. The development of new drugs that can effectively kill malaria parasites is of increasing importance as the threat of drug resistance continues to grow. However, as highlighted above, the findings of this study require further exploration and testing to elucidate or confirm the role of Syk inhibitors as potential drug targets.

Author Contributions: A.P., G.M., A.D., and R.D. conceived of the study and design and supervised the study, contributing to interpretation of data and writing of the paper. G.M., together with I.T., A.D., and R.D., performed experiments. M.C.P. and I.T. contributed to the formulation of results. A.P., F.M.T., A.D., and R.D. have given approval to the final version of the manuscript. All authors have read and agreed to the published version of the manuscript.

Funding: This study was supported by grants from Fondo di Ateneo per la Ricerca 2020.

Acknowledgments: The authors would like to thank Claudio Fozza for his collaboration.

Conflicts of Interest: The authors declare no conflict of interest.

\section{Abbreviations}

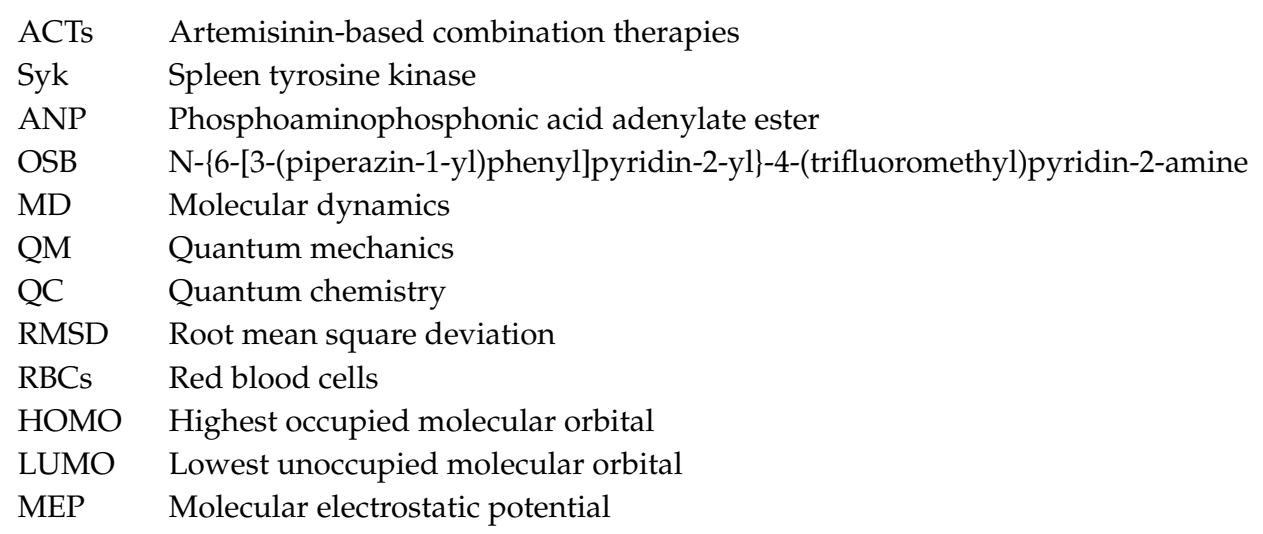

\section{References}

1. Berton, G.; Mocsai, A.; Lowell, C.A. Src and Syk kinases: Key regulators of phagocytic cell activation. Trends Immunol. 2005, 26, 208-214. [CrossRef] [PubMed]

2. Sada, K.; Takano, T.; Yanagi, S.; Yamamura, H. Structure and function of Syk protein-tyrosine kinase. J. Biochem. 2001, 130, 177-186. [CrossRef] [PubMed]

3. Siraganian, R.P.; Zhang, J.; Suzuki, K.; Sada, K. Protein tyrosine kinase Syk in mast cell signaling. Mol. Immunol. 2002, 38, 1229-1233. [CrossRef]

4. Singh, R.; Masuda, E.S.; Payan, D.G. Discovery and development of spleen tyrosine kinase (SYK) inhibitors. J. Med. Chem. 2012, 55, 3614-3643. [CrossRef]

5. Chan, A.C.; Shaw, A.S. Regulation of. antigen receptor signal transduction by protein tyrosine kinases. Curr. Opin. Immunol. 1995, 8, 394-401. [CrossRef]

6. Van Oers, N.S.; Weiss, A. The Syk/ZAP-70 protein tyrosine kinase connection to antigen receptor signalling processes. Semin. Immunol. 1995, 7, 227-236. [CrossRef]

7. Filippakopoulos, P.; Müller, S.; Knapp, S. SH2 domains: Modulators of nonreceptor tyrosine kinase activity. Curr. Opin. Struct. Biol. 2009, 19, 643-649. [CrossRef]

8. Bond, P.J.; Faraldo-Gómez, J.D. Molecular mechanism of selective recruitment of Syk kinases by the membrane antigen-receptor complex. J. Biol. Chem. 2011, 286, 25872-25881. [CrossRef] 
9. Hall, J.; Aulabaugh, A.; Rajamohan, F.; Liu, S.; Kaila, N.; Wan, Z.K.; Ryan, M.; Magyar, R.; Qiu, X. Biophysical and mechanistic insights into novel allosteric inhibitor of spleen tyrosine kinase. J. Biol. Chem. 2012, 10, 7717-7727. [CrossRef]

10. Pantaleo, A.; Ferru, E.; Carta, F.; Mannu, F.; Simula, L.F.; Khadjavi, A.; Turrini, F. Irreversible AE1 Tyrosine Phosphorylation Leads to Membrane Vesiculation in G6PD Deficient Red Cells. PLoS ONE 2011, 6. [CrossRef]

11. Pantaleo, A.; Ferru, E.; Giribaldi, G.; Mannu, F.; Carta, F.; Matte, A.; De Franceschi, L.; Turrini, F. Oxidized and poorly glycosylated band 3 is selectively phosphorylated by Syk kinase to form large membrane clusters in normal and G6PD-deficient red blood cells. Biochem. J. 2009, 2, 359-367. [CrossRef] [PubMed]

12. Pantaleo, A.; Ferru, E.; Carta, F.; Valente, E.; Pippia, P.; Turrini, F. Effect of heterozygous beta thalassemia on the phosphorylative response to Plasmodium falciparum infection. J. Proteom. 2012, 76, 251-258. [CrossRef] [PubMed]

13. Ferru, E.; Giger, K.; Pantaleo, A.; Campanella, E.; Grey, J.; Ritchie, K.; Vono, R.; Turrini, F.; Low, P.S. Regulation of membrane-cytoskeletal interactions by tyrosine phosphorylation of erythrocyte band 3. Blood 2011, 22, 5998-6006. [CrossRef]

14. Ferru, E.; Pantaleo, A.; Carta, F.; Mannu, F.; Khadjavi, A.; Gallo, V.; Turrini, F. Thalassemic erythrocytes release microparticles loaded with hemichromes by redox activation of p72Syk kinase. Haematologica 2014, 99, 570-578. [CrossRef] [PubMed]

15. Kesely, K.R.; Pantaleo, A.; Turrini, F.M.; Olupot-olupot, P.; Low, P.S. Inhibition of an Erythrocyte Tyrosine Kinase with Imatinib Prevents Plasmodium falciparum Egress and Terminates Parasitemia. PLoS ONE 2016, 11, e0164895. [CrossRef] [PubMed]

16. Pantaleo, A.; Kesely, K.R.; Pau, M.C.; Tsamesidis, I.; Schwarzer, E.; Skorokhod, O.A.; Chien, H.D.; Ponzi, M.; Bertuccini, L.; Low, P.S.; et al. Syk inhibitors interfere with erythrocyte membrane modification during $P$ falciparum growth and suppress parasite egress. Blood 2017, 130, 1031-1040. [CrossRef] [PubMed]

17. Tsamesidis, I.; Reybier, K.; Marchetti, G.; Pau, M.C.; Virdis, P.; Fozza, C.; Nepveu, F.; Low, P.S.; Turrini, F.M.; Pantaleo, A. Syk kinase inhibitors synergize with artemisinins by enhancing oxidative stress in Plasmodium falciparum-parasitized erythrocytes. Antioxidants 2020, 9, 753. [CrossRef]

18. Sechi, M.; Derudas, M.; Dallocchio, R.; Dessì, A.; Bacchi, A.; Sannia, L.; Carta, F.; Palomba, M.; Ragab, O.; Chan, C.; et al. Design and Synthesis of Novel Indole -Diketo Acid Derivatives as HIV-1 Integrase Inhibitors. J. Med. Chem. 2004, 47, 5298-5310. [CrossRef]

19. Pani, G.; Dessì, A.; Dallocchio, R.; Scherm, B.; Azara, E.; Delogu, G.; Migheli, Q. Natural Phenolic Inhibitors of Trichothecene Biosynthesis by the Wheat Fungal Pathogen Fusarium culmorum: A Computational Insight into the Structure-Activity Relationship. PLOS ONE 2016, 11, e0157316. [CrossRef]

20. Marangon, E.; Citterio, M.; Sala, F.; Barisone, E.; Lippi, A.A.; Rizzari, C.; Biondi, A.; D'Incalci, M.; Zucchetti, M. Pharmacokinetic profile of imatinib mesylate and N-desmethyl-imatinib (CGP 74588) in children with newly diagnosed Ph+ acute leukemias. Cancer Chemother. Pharmacol. 2009, 3, 563-566. [CrossRef]

21. Champagne, M.A.; Capdeville, R.; Krailo, M.; Qu, W.; Peng, B.; Rosamilia, M.; Therrien, M.; Zoellner, U.; Blaney, S.M.; Bernstein, M. Imatinib mesylate (STI571) for treatment of children with Philadelphia chromosome-positive leukemia: Results from a Children's Oncology Group phase 1 study. Blood 2004, 9, 2655-2660. [CrossRef] [PubMed]

22. Annesley, C.E.; Brown, P. Novel agents for the treatment of childhood acute leukemia. Ther. Adv. Hematol. 2015, 6, 61-79. [CrossRef] [PubMed]

23. Weinblatt, M.E.; Genovese, M.C.; Ho, M.; Rosiak-Jedrychowicz, S.H.K.; Kavanaugh, A.; Millson, D.S.; Leon, G.; van der Heijde, D. Effects of Fostamatinib, an Oral Spleen Tyrosine Kinase Inhibitor, in Rheumatoid Arthritis Patients with an Inadequate Response to Methotrexate: Results from a Phase III, Multicenter, Randomized, Double-Blind, Placebo-Controlled, Parallel-Group Study. Arthritis Rheumatol. 2014, 66, 3255-3264. [CrossRef] [PubMed]

24. Podolanczuk, A.; Lazarus, A.H.; Crow, A.R.; Grossbard, E.; Bussel, J.B. Of mice and men: An open-label pilot study for treatment of immune thrombocytopenic purpura by an inhibitor of Syk. Blood 2009, 113, 3154-3160. [CrossRef] [PubMed]

25. Tauzin, S.; Ding, H.; Burdevet, D.; Borisch, B.; Hoessli, D.C. Membrane-associated signaling in human B-lymphoma lines. Exp. Cell. Res. 2011, 2, 151-162. [CrossRef] 
26. Friedberg, J.W.; Sharman, J.; Sweetenham, J.; Johnston, P.B.; Vose, J.M.; LaCasce, A.; Schaefer-Cutillo, J.; De Vos, S.; Sinha, R.; Leonard, J.P.; et al. Inhibition of Syk with fostamatinib disodium has significant clinical activity in non-Hodgkin Lymphoma and chronic lymphocytic leukemia. Blood 2010, 115, 2578-2585. [CrossRef]

27. Coffey, G.; DeGuzman, F.; Inagaki, M.; Pak, Y.; MDelaney, S.; Ives, D.; Betz, A.; Jia, Z.J.; Pandey, A.; Baker, D.; et al. Specific Inhibition of Spleen Tyrosine Kinase Suppresses Leukocyte Immune Function and Inflammation in Animal Models of Rheumatoid Arthritis. J. Pharmacol. Exp. Ther. 2011, 340, 350-359. [CrossRef]

28. Spurgeon, S.E.; Coffey, G.; Fletcher, L.B.; Burke, R.; Tyner, J.W.; Druker, B.J.; Loriaux, M.M. The Selective Syk Inhibitor P505-15 (PRT062607) Inhibits B Cell Signaling and Function In Vitro and In Vivo and Augments the Activity of Fludarabine in Chronic Lymphocytic Leukemia. J. Pharmacol. Exp. Ther. 2013, 344, 378-387. [CrossRef]

29. Hisamichi, H.; Naito, R.; Toyoshima, A.; Kawano, N.; Ichikawa, A.; Orita, A.; Tsukamoto, S. Synthetic studies on novel Syk inhibitors. Part 1: Synthesis and structure-activity relationships of pyrimidine-5-carboxamide derivatives. Bioorg. Med. Chem. 2005, 13, 4936-4951. [CrossRef]

30. Yi, Y.; Son, Y.; Ryou, C.; Sung, G.; Kim, J.; Cho, J.Y. Functional Roles of Syk in Macrophage-Mediated Inflammatory Responses. Mediat. Inflamm. 2014, 2014, 1-12. [CrossRef]

31. Bordin, L.; Brunati, A.M.; Donella-Deana, A.; Baggio, B.; Toninello, A.; Clari, G. Band 3 is an anchor protein and a target for SHP-2 tyrosine phosphatase in human erythrocytes. Blood 2002, 100, 276-282. [CrossRef] [PubMed]

32. Harrison, M.L.; Isaacson, C.C.; Burg, D.L.; Geahlen, R.L.; Low, P.S. Phosphorylation of human erythrocyte band 3 by endogenous p72syk. J. Biol. Chem. 1994, 269, 955-959. [PubMed]

33. Bordin, L.; Zen, F.; Ion-Popa, F.; Barbetta, M.; Baggio, B.; Clari, G. Band 3 tyr-phosphorylation in normal and glucose-6-phospate dehydrogenase-deficient human erythrocytes. Mol. Membr. Biol. 2005, 5, 411-420. [CrossRef]

34. Villaseñor, A.G.; Kondru, R.; Hoangdung, H.; Wang, S.; Papp, E.; Shaw, D.; Barnett, J.W.; Browner, M.F.; Kuglstatter, A. Structural Insights for Design of Potent Spleen Tyrosine Kinase Inhibitors from Crystallographic Analysis of Three Inhibitor Complexes. Chem. Biol. Drug Des. 2009, 73, 466-470. [CrossRef] [PubMed]

35. Castillo, M.; Forns, P.; Erra, M.; Lopez, M.; Maldonado, M.; Orellana, A.; Carreno, C.; Ramis, I.; Miralpeix, M.; Vidal, B. Highly potent aminopyridines as Syk kinase inhibitors. Bioorg. Med. Chem. Lett. 2012, 22, 5419-5423. [CrossRef] [PubMed]

36. Al-Sabagh, A.M.; Nasser, N.M.; Farag, A.A.; Migahed, M.A.; Eissa AM, F.; Mahmoud, T. Structure effect of some amine derivatives on corrosion inhibition efficiency for carbon steel in acidic media using electrochemical and Quantum Theory Methods. Egypt. J. Pet. 2013, 22, 101-116. [CrossRef]

37. Traxler, P.; Furet, P. Strategies toward the Design of Novel and Selective Protein Tyrosine Kinase Inhibitors. Pharmacol. Ther. 1999, 82, 195-206. [CrossRef]

38. Thoma, G.; Smith, A.B.; Eis, M.J.; Van Vangrevelinghe, E.; Blanz, J.; Aichholz, R.; Zerwes, H. Discovery and Profiling of a Selective and Efficacious Syk Inhibitor. J. Med. Chem. 2015, 58, 1950-1963. [CrossRef]

39. Miah SM, S.; Sada, K.; Tuazon, P.T.; Ling, J.; Maeno, K.; Kyo, S.; Yamamura, H. Activation of Syk Protein Tyrosine Kinase in Response to Osmotic Stress Requires Interaction with p21-Activated Protein Kinase Pak2/ $\gamma$-PAK. Mol. Cell. Biol. 2004, 24, 71-83. [CrossRef]

40. Grädler, U.; Schwarz, D.; Dresing, V.; Musil, D.; Bomke, J.; Frech, M.; Wegener, A. Structural and biophysical characterization of the Syk activation switch. J. Mol. Biol. 2013, 425, 309-333. [CrossRef]

41. Zeifman, A.A.; Titov, Y.; Svitanko, I.V.; Rakitina, T.V.; Lipkin, A.V.; Stroylov, V.S.; Chilov, G.G. Rational design and synthesis of novel Syk-kinase inhibitors. Mendeleev Commun. 2012, 22, 73-74. [CrossRef]

42. Padilla, F.; Bhagirath, N.; Chen, S.; Chiao, E.; Goldstein, D.M.; Hermann, J.C.; Lucas, M.C. Pyrrolopyrazines as selective spleen tyrosine kinase inhibitors. J. Med. Chem. 2013, 56, 1677-1692. [CrossRef]

43. Jiang, M.; Liu, R.; Chen, Y.; Zheng, Q.; Fan, S.; Liu, P. A combined experimental and computational study of Vam3, a derivative of resveratrol, and syk interaction. Int. J. Mol. Sci. 2014, 15, 17188-17203. [CrossRef] [PubMed]

44. Trager, W.; Jensen, J.B. Human malaria parasites in continuous culture. Science 1976, 193, 673-675. [CrossRef] [PubMed] 
45. De Lucia, S.; Tsamesidis, I.; Pau, M.C.; Kesely, K.R.; Pantaleo, A.; Turrini, F. Induction of high tolerance to artemisinin by sub-lethal administration: A new in vitro model of P. falciparum. PLoS ONE 2018, 13. [CrossRef] [PubMed]

46. Fandeur, T.; Bonnefoy, S.; Mercereau-Puijalon, O. In vivo and in vitro derived Palo Alto lines of Plasmodium falciparum are genetically unrelated. Mol. Biochem. Parasitol. 1991, 47, 167-178. [CrossRef]

47. Lambros, C.; Vanderberg, J.P. Synchronization of Plasmodium falciparum erythrocytic stages in culture. J. Parasitol. 1979, 65, 418-420. [CrossRef]

48. Rivadeneira, E.M.; Wasserman, M.; Espinal, C.T. Separation and concentration of schizonts of Plasmodium falciparum by Percoll gradients. J. Protozool. 1983, 30, 367-370. [CrossRef]

49. Le Nagard, H.; Vincent, C.; Mentré, F.; Le Bras, J. Online analysis of in vitro resistance to antimalarial drugs through nonlinear regression. Comput. Methods Programs Biomed. 2010, 104, 10-18. [CrossRef]

50. Kaddouri, H.; Nakache, S.; Houzé, S.; Mentré, F.; Le Bras, J. Drug Susceptibility of Plasmodium falciparum Clinical Isolates from Africa using Plasmodium Lactate Dehydrogenase Immunodetection Assay and inhibitory Emax model for precise IC50 measurement. Antimicrob. Agents Chemother. 2006, 50, 3343-3349. [CrossRef]

51. Laemmli, U.K. Cleavage of structural proteins during the assembly of the head of bacteriophage T4. Nature 1970, 227, 680-685. [CrossRef]

52. Mohamadi, F.; Richards, N.G.J.; Guida, W.C.; Liskamp, R.; Lipton, M.; Caufield, C.; Chang, G.; Hendrickson, T.; Still, W.C. Macromodel-an integrated software system for modeling organic and bioorganic molecules using molecular mechanics. J. Comput. Chem. 1990, 11, 440-467. [CrossRef]

53. Chang, G.; Guida, W.C.; Still, W.C. An internal-coordinate Monte Carlo method for searching conformational space. J. Am. Chem. Soc. 1989, 111, 4379-4386. [CrossRef]

54. Gasteiger, J.; Marsili, M. Iterative partial equalization of orbital electronegativity-A rapid access to atomic charges. Tetrahedron 1980, 36, 3219-3228. [CrossRef]

55. Frisch, M.J.; Trucks, G.W.; Schlegel, H.B.; Scuseria, G.E.; Robb, M.A.; Cheeseman, J.R.; Scalmani, G.; Barone, V.; Petersson, G.A.; Nakatsuji, H.; et al. Gaussian 09; Gaussian Inc.: Wallingford, CT, USA, 2009.

56. Dennington, R.; Keith, T.; Millam, J. Gauss View, Version 5; Semichem Inc.: Shawnee Mission, KS, USA, 2009.

57. Sanner, M.F. Python: A programming language for software integration and development. J. Mol. Graph. $1999,17,57-61$.

58. Morris, G.M.; Goodsell, D.S.; Halliday, R.S.; Huey, R.; Hart, W.E.; Belew, R.K.; Olson, A.J. Automated docking using a Lamarckian genetic algorithm and an empirical binding free energy function. J. Comput. Chem. 1998, 19, 1639-1662. [CrossRef]

59. Huey, R.; Morris, G.M.; Olson, A.J.; Goodsell, D.S. A semiempirical free energy force field with charge-based desolvation. J. Comput. Chem. 2007, 28, 1145-1152. [CrossRef]

60. Berman, H.M.; Westbrook, J.; Feng, Z.; Gilliland, G.; Bhat, T.N.; Weissig, H.; Shindyalov, I.N.; Bourne, P.E. The Protein Data Bank. Nucleic Acids Res. 2000, 28, 235-242. [CrossRef]

61. Case, D.A. AMBER 14; University of California: San Francisco, CA, USA, 2014.

62. Joung, I.S.; Cheatham, T.E. Determination of Alkali and Halide Monovalent Ion Parameters for Use in Explicitly Solvated Biomolecular Simulations. J. Phys. Chem. B 2008, 112, 9020-9041. [CrossRef]

63. Pettersen, E.F.; Goddard, T.D.; Huang, C.C.; Greenblatt, D.M.; Meng, E.C.; Ferrin, T.E. UCSF Chimera-A visualization system for exploratory research and analysis. J. Comput. Chem. 2004, 25, 1605-1612. [CrossRef]

64. Humphrey, W.; Dalke, A.; Schulten, K. VMD: Visual molecular dynamics. J. Mol. Graph. 1996, 14, 33-38. [CrossRef] [PubMed]

65. Kaus, J.W.; Pierce, L.T.; Walker, R.C.; McCammon, J.A. Improving the Efficiency of Free Energy Calculations in the Amber Molecular Dynamics Package. J. Chem. Theory Comput. 2013, 9, 4131-4139. [CrossRef]

66. Laskowski, R.A.; Swindells, M.B. LigPlot+: Multiple Ligand-Protein Interaction Diagrams for Drug Discovery. J. Chem. Inf. Model. 2011, 51, 2778-2786. [CrossRef] [PubMed]

67. Dessì, A.; Peluso, P.; Dallocchio, R.; Weiss, R.; Andreotti, G.; Allocca, M.; Aubert, E.; Pale, P.; Mamane, V.; Cossu, S. Rational design, synthesis, characterization and evaluation of iodinated 4,4'-bipyridines as new transthyretin fibrillogenesis inhibitors. Molecules 2020, 25, 2213. [CrossRef]

68. Wang, Z.; Sun, H.; Yao, X.; Li, D.; Xu, L.; Li, Y.; Tian, S.; Hou, T. Comprehensive evaluation of ten docking programs on a diverse set of protein-ligand complexes: The prediction accuracy of sampling power and scoring power. Phys. Chem. Chem. Phys. 2016, 18, 12964-12975. [CrossRef] 
69. Irwin, J.J.; Shoichet, B.K. Docking screens for novel ligands conferring new biology. J. Med. Chem. 2016, 59, 4103-4120. [CrossRef]

70. Ferreira, L.G.; dos Santos, R.N.; Oliva, G.; Andricopulo, A.D. Molecular docking and structure-based drug design strategies. Molecules 2015, 20, 13384-13421. [CrossRef] 